${ }^{4}$ Scragg J, Rubidge C, Wallace HL. Typhoid fever in African and Indian children in Durban. Arch Dis Child 1969:44:18-28.

${ }^{5}$ McKendrick MW, Geddes AM, Farrell ID. Trimethoprim in enteric fever. In: Penti P, Grass GG, eds. Current chemotherapy and immunotherapy. Proceedings of the 12th International Congress of Chemotherapy. (Florence 1981.) Vol. 2. Washington DC: American Society for Microbiology, 1982:957-8.

${ }^{6}$ Nelson JD, Kusmiesz H, Jackson LH. Treatment of salmonella gastroenteritis with ampicillin, amoxicillin or placebo. Pediatrics 1980;65:1125-30.

Correspondence to $\mathrm{Dr} \mathrm{K}$ C Chin, University of Birmingham, Department of Paediatrics and Child Health, East Birmingham Hospital, Bordesley Green East, Birmingham B9 5ST, England.

Received 21 July 1986

\title{
Fluoride treatment in corticosteroid induced osteoporosis
}

\author{
F REJOU, R DUMAS, C BELON, P J MEUNIER, AND C EDOUARD
}

Clinique des Maladies des Enfants et d'Hygiène du Premier Age, Hôpital Saint-Charles, Montpellier Cedex, and Unité Inserm 234, Faculté Alexis Carrel, Lyon, France

SUMMARY Severe osteoporosis with multiple vertebral fractures occurred in two girls receiving prolonged high dose corticosteroids for relapsing dermatomyositis. Sodium fluoride, supplemented with calcium and vitamin $\mathrm{D}$, helped control secondary osteoporosis in one case and should be considered as part of the curative treatment of corticoid induced osteoporosis.

Sodium fluoride is now used in idiopathic osteoporosis of aging adults, ${ }^{12}$ as it should be able to increase bone mass. Prolonged high doses of treatment with corticosteroids may produce severe osteoporosis in children. The histomorphometric and histodynamic method ${ }^{3}$ represents a quantitative approach to the evaluation of bone disease under treatment with fluoride.

\section{Case reports}

Case 1. A 10 year old, prepubertal girl was treated for dermatomyositis. From August 1980 to December 1982 she received the following treatment and dosages: prednisone $0.6-2 \mathrm{mg} / \mathrm{kg} /$ day, with calcifediol $100 \mu \mathrm{g} /$ day up to November 1981 and then alfacalcidol 0.5-1 $\mu \mathrm{g} /$ day up to December 1982, and also hydrochlorothiazide $75 \mathrm{mg} /$ day. No height gain was observed from January 1981 to December 1982. At this time her height was $128 \mathrm{~cm}$ and dermatomyositis was stable, but treatment with corticosteroids induced a severe osteoporosis and multiple vertebral fractures (D6, D7, D10, D12, and L5).

From December 1982 to April 1984 she received prednisone $0 \cdot 6-1 \cdot 1 \mathrm{mg} / \mathrm{kg} / \mathrm{day}$ on alternate days with alfacalcidol $(0.5 \mu \mathrm{g} /$ day $)$, calcium carbonate $(1.5$ $\mathrm{g} /$ day), and hydrochlorothiazide. Sodium fluoride was given at a dose of $1 \mathrm{mg} / \mathrm{kg} / \mathrm{day}$ for 16 months.
The height gain during this treatment was $10 \mathrm{~cm}$ and the girl remained impubertal. No other vertebral fractures occurred, and bone $x$ ray profile has improved.

Case 2. This 7 year old girl presented with dermatomyosistis in March 1981. She received an average dose of prednisone $1.4 \mathrm{mg} / \mathrm{kg} / \mathrm{day}$ with alfacalcidol $0.25-0.75 \mu \mathrm{g} /$ day and hydrochlor othiazide $75 \mathrm{mg} /$ day without calcium supplementao tion because of hypercalciuria. In October 1982 hex. height was $123 \mathrm{~cm}$ and the presence of multiple vertebral fractures (eight vertebras) revealed $\vec{a}$ severe osteoporosis associated with renal lithiasis. From June 1983 to May 1985 the dermatomyositis relapsed and treatment included prednisone $1.1 \mathrm{mg} / \mathrm{kg} /$ day in conjunction with sodium fluoride $1 \mathrm{mg} / \mathrm{kg} /$ day, alfacalcidol $0.5 \mu \mathrm{g} / \mathrm{day}$, and hydrochlorothiazide $75 \mathrm{mg} /$ day. During this time, the $x$ ray profile of the spine improved and no other vertebral fractures occurred. At the end of the study the girl remained prepubertal and ner height was $135 \mathrm{~cm}$.

In both cases, after tetracycline double labelling, a bone biopsy specimen was taken before and after treatment with fluoride. The histomorphometric and histodynamic variables were compared (Table).

\section{Discussion}

In both children the natural history and bone radiology during extended treatment with corticosteroids for dermatomyositis seemed typical of corticosteroid induced osteoporosis. We could not study bone photon absorptiometry, but bone biopsy specimens were contributive: appreciable decrease of trabecular bone volume with decrease of the calcification rates and increased trabecular resorption 
Table Histomorphometric variables in bone biopsy specimens taken from the two cases

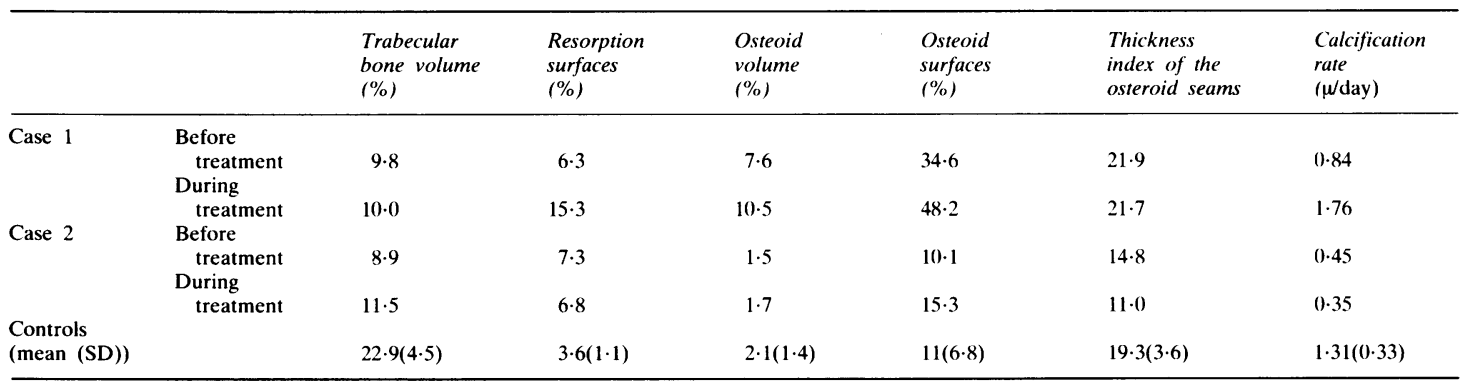

Trabecular bone volume=percentage of trabecular bone tissue in total spongy space.

Resorption surfaces $=$ percentage of total trabecular resorption surface area.

Osteoid volume $=$ trabecular osteoid volume expressed as a percentage of total bone volume

Osteoid surfaces=percentage of trabecular surface area covered with osteoid

Thickness index of the osteoid seams=ratio of osteoid volume to osteoid surface area multiplied by factor of 100 .

Calcification rate $=$ calculated by double labelling of the calcification front with tetracycline .

surfaces are characteristic of adult corticosteroid induced osteoporosis. ${ }^{3}$ Some criteria of diminished bone apposition (decrease in the thickness of the osteoid seams and increased osteoid surfaces), however, were seldom observed. Few data are available on corticosteroid induced osteoporosis in children, but it does not seem to be different from the adult disease. ${ }^{45}$

Curative treatment is still widely unknown. In a previous unpublished study we have shown that the use of calcium supplementation with alfacalcidol improved the calcium absorption in some cases but did not allow us to restore a sufficient bone mass or prevent new vertebral fractures. (Rejou F, Dumas R, Belon C, Meunier P J, Edouard C, Jean R. Bone histomorphometric studies compared with calcium absorption in juvenile corticoid-induced osteoporosis. Presented at European Society for Pediatric Research Annual Meeting, Cambridge, England, 16-20 September 1984.) Sodium fluoride is now an integral part of the treatment of idiopathic adult osteoporosis $^{1}$ and has been used in conjunction with calcium and vitamin $\mathrm{D}$ in corticosteroid induced osteoporosis. ${ }^{2}$ In adults treatment with fluoride provides vertebral pain relief and irregular radiographic improvement. Histomorphometric studies reveal increases of trabecular bone volume, osteoid surfaces, and thickness index of the osteoid seams in most cases. The calcification rate has showed little modification when moderate doses of fluoride with calcium have been used in adult patients. The risks of treatment with fluoride are osteomalacia, ${ }^{2}$ after a long course of treatment, joint pains, and digestive troubles. We did not observe such side effects in these two cases, but the treatment did not exceed two years. Clinical improvement and the absence of new vertebral fractures were observed, in spite of relapsing dermatomyositis in one case. Histomorphometric data after a year of treatment with fluoride showed inconsistent improvement: trabecular bone volume was unchanged and the calcification rate increased in one case. There is no evidence, however, that fluoride induced bone changes reflect an increase in mechanical strength.

We believe that treatment with fluoride together with calcium and alfacalcidol must be reserved for children presenting with severe corticosteroid induced osteoporosis. A bone biopsy examination with histomorphometric study seems useful in this situation. Further studies are needed to confirm these preliminary results.

\section{References}

${ }^{1}$ Riggs BL, Jowsey J, Kelly PJ, Hoffman DL, Arnaud CD. Studies on pathogenesis and treatment in post menopausal and senile osteoporosis. Clin Endocrinol Metab 1973;2:317-32.

${ }^{2}$ Kanis JA, Meunier PJ. Should we use fluoride to treat osteoporosis? A review. $Q J$ Med 1984;210:145-64.

${ }^{3}$ Bressot C, Meunier PJ, Chapuy MC, Lejeune E, Edouard C, Darby AJ. Histomorphometric profile, pathophysiology and reversibility of corticosteroid-induced osteoporosis. Metab Bone Dis Relat Res 1979;1:303-11.

${ }^{4}$ Hahn TJ, Halstead LR, Teitelbaum SM, Hahn B. Altered mineral metabolism in glucocorticoid-induced osteopenia. J Clin Invest 1979;64:653-5.

${ }^{5}$ Harrison HF, Harrison MC, eds. Disorders of calcium and phosphate metabolism in childhood and adolescence. Philadelphia: WB Saunders, 1979.

Correspondence to Dr F Rejou, Clinique des Maladies des Enfants et d'Hygiène du Premier Age, Hôpital Saint-Charles, 34059 Montpellier, France.

Received 22 July 1986 